\title{
Spatial variability of air pollutants in a megacity characterized by mobile measurements: Chemical homogeneity under haze conditions
}

\author{
Reza Bashiri Khuzestani ${ }^{1, \mathrm{a}, \star}$, Keren Liao ${ }^{1, \star}$, Qi Chen ${ }^{1, *}$, Ying Liu ${ }^{1}$, Yan Zheng ${ }^{1}$, Xi Cheng ${ }^{1}$, Tianjiao Jia ${ }^{1}$, \\ Xin $\mathrm{Li}^{1}$, Shiyi Chen ${ }^{1}$, Guancong Huang ${ }^{1}$ \\ $5 \quad{ }^{1}$ State Key Joint Laboratory of Environmental Simulation and Pollution Control, BIC-ESAT and IJRC, College of \\ Environmental Sciences and Engineering, Peking University, Beijing, 100871, China \\ ${ }^{a}$ Now at: Faculty of Civil, Water and Environmental Engineering, School of Engineering, Shahid Beheshti University, Tehran, \\ Iran. \\ ${ }^{\star}$ These authors contributed equally to this work. \\ ${ }^{*}$ Correspondence to: Qi Chen (qichenpku@pku.edu.cn)
}

\begin{abstract}
Characterization of the spatial distributions of air pollutants on an intracity scale is important for understanding localized sources, secondary formation, and human exposure. In this study, we conducted in situ mobile measurements for the chemical composition of fine particles, volatile organic compounds (VOCs), oxygenated VOCs (OVOCs), and common gas pollutants in winter in the megacity of Beijing. The spatial variations of these gaseous and particulate pollutants under different pollution conditions are investigated. During the less-polluted periods, a large spatial variability exists in the inorganic composition of fine particles, suggesting a wide range of particle neutralization in Beijing. Significant spatial variations are also observed in the composition of organic aerosol (OA), which is mainly driven by local emissions of primary OA from vehicle and cooking exhaust. The spatial variations of VOCs and OVOCs vary by species. In general, hydrocarbon compounds show a large spatial variability driven by traffic emissions, while secondary OVOCs are more spatially homogeneous in concentration. Other gas pollutants show relatively low spatial variabilities, although hot spots of concentration frequently appear which are plausibly caused by high-emitting plumes as well as fast on-road ozone titration. During the haze periods, the spatial variabilities of air pollutants are largely reduced because of the contribution of regional transport. Hydrocarbons and less-oxygenated OVOCs show good positive spatial-temporal correlations in concentration. More-oxygenated OVOCs show good positive correlations among themselves and moderate negative correlations with hydrocarbons, less-oxygenated OVOCs, and particulate components. The results highlight the potential role of chemical homogeneity on the SOA production in the megacity under haze conditions. On the other hand, the spatial heterogeneity of air pollution calls a future need of using fine-resolution models to evaluate human exposure and pollution control strategies.
\end{abstract}




\section{Introduction}

Air quality degradation has become a serious problem in developing countries (Huang et al., 2014; Khuzestani et al., 2017). Cities in northern China suffer from severe haze events, especially in winter (Huang et al., 2014). High concentrations of volatile organic compounds (VOCs) and nitrogen oxides $\left(\mathrm{NO}_{x}=\mathrm{NO}+\mathrm{NO}_{2}\right)$ contribute to high atmospheric oxidation capacity to produce ozone $\left(\mathrm{O}_{3}\right)$ and secondary aerosol (Lu et al., 2019b; Wang et al., 2017). The mass concentrations of particles having aerodynamic diameter less than $2.5 \mu \mathrm{m}\left(\mathrm{PM}_{2.5}\right)$ may reach up to several hundreds of $\mu \mathrm{g} \mathrm{m}^{-3}$ and $\mathrm{O}_{3}$ concentrations may exceed 100 ppbv in megacities. Both of high exposures of $\mathrm{PM}_{2.5}$ and $\mathrm{O}_{3}$ are of great concern to human health (Liu et al., 2016; Bell et al., 2006).

Tremendous efforts have been made to characterize air pollutants in populated urban areas in China (Li et al., 2017; Wang et al., 2017; Quan and Jia, 2020). In most studies, stationary measurements were conducted to obtain temporal variations of pollutants for the analysis of sources and formation mechanisms. Sulfate, nitrate, ammonium, and organic aerosol (OA) are the major chemical components of $\mathrm{PM}_{2.5}$ in cities in China ( $\mathrm{Li}$ et al., 2017). Their mass concentrations show decreases nationwide since 2013 as a result of the emission reduction of gaseous precursors such as sulfur dioxide $\left(\mathrm{SO}_{2}\right), \mathrm{NO}_{\mathrm{x}}$, and VOCs under clean air actions as well as the changes of meteorological conditions (Zhang et al., 2019). In Beijing, the contribution of secondary OA (SOA) has significantly increased since 2018, while the contribution of primary OA (POA) from burning of coal and biomass (biofuel) and cooking emissions have decreased (Lei et al., 2021). Characterization of organic precursors including VOCs and semivolatile and intermediate volatility organic compounds (S/IVOCs) is crucial for understanding the SOA production. Previous studies have shown that besides alkanes, aromatics and oxygenated VOCs (OVOCs) are abundant in cities in China (Mozaffar and Zhang, 2020; Li et al., 2016; Guo et al., 2017). These VOCs may come from a variety of anthropogenic sources (e.g., vehicles, industries, solvent usage, coal and biomass burning, and household use of volatile chemical products etc.) and have great potential to form $\mathrm{O}_{3}$ and SOA.

On an intracity scale, local emissions, advection, and boundary layer evolution may affect the spatial distributions of air pollutants. Tower measurements have shown greater vertical gradients of particulate matter (PM) concentration and composition during clean periods than haze periods in Beijing, which is attributed to the influence of both physical (e.g., regional transport, mixing layer height, and inversions etc.) and chemical processes (e.g., gas-particle partitioning and aqueous processing) (Zhou et al., 2018). Significant vertical gradients also present in the concentrations of VOCs in cities, which can be affected by transport of air mass, vertical diffusion, and species reactivity (Sun et al., 2018; Mo et al., 2020). Moreover, grid sampling and simultaneous measurements at multiple sites are often used to investigate the spatial variations of air pollutants on sparse spatial scales. Previous studies show that the surface concentrations of VOCs and $\mathrm{PM}_{2.5}$ components vary because of different source contributions in metropolitan areas in China (Chen et al., 2020; Song et al., 2021).

To better characterize the spatial distributions of air pollutants, mobile laboratory equipped with fast response in situ instruments have been widely used in Europe and United States (Kolb et al., 2004). For example, mobile measurements in 
Pittsburgh and Zurich indicate different spatial variability of PM composition (Tan et al., 2014; Gu et al., 2018; Ye et al., 2018; Mohr et al., 2011; Elser et al., 2016). While primary carbonaceous sources perhaps lead to the large spatial heterogeneity of PM composition in Pittsburgh, a rather uniform distribution was observed in the metropolitan area of Zurich especially during thermal inversions over the Swiss plateau, highlighting the complexity of urban air pollution. However, the development and application of advanced mobile laboratory are lagged in China. Mobile measurements have been conducted to obtain the spatial distributions of $\mathrm{SO}_{2}, \mathrm{NO}_{x}$, carbon monoxide (CO), and black carbon (BC) as well as $\mathrm{NO}_{2}$ and $\mathrm{SO}_{2}$ column densities for the evaluation of regional transport routes in North China Plain (NCP) and urban air quality (Wang et al., 2009; Wang et al., 2011; Zhu et al., 2016; Wu et al., 2018). Recent deployments of online mass spectrometers in mobile laboratory have successfully captured the spatial distributions of VOCs and $\mathrm{PM}_{2.5}$ composition in cities in China, which can be particularly useful for identifying emission sources (Wang et al., 2021c; Liang et al., 2020; Liao et al., 2021).

In this study, we conducted in situ sampling with gas analyzers and advanced mass spectrometers on a newly developed mobile laboratory platform in winter in the megacity of Beijing. Spatial distributions of the mass concentrations of non-refractory $\mathrm{PM}_{2.5}$ (NR-PM 2.5 ) components (i.e., OA, nitrate, sulfate, ammonium, and chloride), VOC and OVOC species, and common gas pollutants such as $\mathrm{SO}_{2}, \mathrm{CO}, \mathrm{NO}, \mathrm{NO}_{2}$, and $\mathrm{O}_{3}$ are obtained. The spatial variabilities of these gaseous and particulate pollutants under different pollution conditions are investigated to provide new insights to urban pollution and to improve our understanding of human exposure.

\section{Methods}

On-road measurements were conducted by the PKU mobile laboratory (Figure S1 in the Supplement) on the 4th Ring Road of Beijing on 7-21 November 2018. The 4th Ring Road is a 65-km-long highway that passes through commercial, industrial, and residential areas. To show the spatial characteristics, the measurement area is categorized into 4 zones: Zone NE, Zone NW, Zone SE, and Zone SW (Figure S2 in the Supplement). Zone SE and Zone SW are close to industrial facilities, while Zone NE and Zone NW are mostly commercial and residential areas. The average traffic volume on the 4th Ring Road is about 40008000 vehicles per hour, and over $90 \%$ of the fleet consisted of light duty gasoline vehicles (LDGVs) that meet National Stage III to $\mathrm{V}$ emission standards.

The measurements started at around 9:00 a.m. and went one cycle after another till 4:00 p.m. Each cycle took approximately $70 \mathrm{~min}$ with a mean speed of $60 \mathrm{~km} \mathrm{~h}^{-1}$. Self-contamination from the vehicle exhaust is negligible for a vehicle speed over 30 $\mathrm{km} \mathrm{h}^{-1}$ (Liao et al., 2021). A suite of instruments was deployed in the mobile laboratory. Gas pollutants were detected by gas analyzers including $\mathrm{NO}_{2}$ (Teledyne, T500U), NO-NO (Ecotech, EC9841A), $\mathrm{SO}_{2}$ (Ecotech, EC9850A), CO (Ecotech, EC9830A), and $\mathrm{O}_{3}$ (Ecotech, EC9810A). The chemical composition of NR-PM 2.5 was measured by an Aerodyne time-of-flight aerosol chemical speciation monitor (TOF-ACSM) with $\mathrm{PM}_{2.5}$ lens and a capture vaporizer (Zheng et al., 2020). The uncertainty for the mass concentrations of NR-PM 2.5 and its components is about $30 \%$ (Canagaratna et al., 2007). The positive 
matrix factorization (PMF) analysis was performed on the OA mass spectra by using the Igor PMF evaluation tool (PET, version 3.00B). Five OA factors were resolved including hydrocarbon-like OA (HOA), cooking-related OA (COA), and three oxygenated OA (OOAs). The common OA factors related to biomass burning (BBOA) or coal burning (CCOA) were not resolved in this data set and were perhaps mixed with OOAs (Liao et al., 2021). Their contributions to OA were however expected to be small because of the stringent emission control in NCP (Zheng et al., 2020; Duan et al., 2020). VOCs and OVOCs were detected by an Ionicon proton transfer reaction-quadrupole ion guide time-of-flight mass spectrometer (PTRQiTOF). The overall quantification uncertainties are $<20 \%$ for calibrated species and $19 \%$ and $33 \%$ for uncalibrated species with known and unknown reaction rate constants $\left(K_{\text {ptr }}\right)$, respectively (Huang et al., 2019). Table S1 in the Supplement lists the $K_{\text {ptr }}$ values, the mean concentrations, and the tentative categorization of VOCs and OVOCs measured herein. Detailed information about the campaign, sampling system, instrument operation, calibration and data analysis has been described elsewhere (Liao et al., 2021).

Figure S3 in the Supplement shows the time series of mass concentrations of air pollutants measured at the PKU campus roof site during the campaign. This site is located between the 4th and the 5th north Ring Roads, representing a typical urban environment in Beijing (Cheng et al., 2021). In this study, we classified clean $\left(<35 \mu \mathrm{g} \mathrm{m}^{-3}\right)$, haze $\left(>75 \mu \mathrm{g} \mathrm{m}{ }^{-3}\right)$, and non-haze $\left(<75 \mu \mathrm{g} \mathrm{m}^{-3}\right)$ days based on the daily mean $\mathrm{PM}_{2.5}$ mass concentrations for the measurements. Moreover, we computed a batch of 12-hour backward trajectories for the height of $3 \mathrm{~m}$ around the 4th Ring Road from the HYSPLIT model to investigate the influence of urban background and regional transport on our measurements during the haze day (Stein et al., 2015). We set the start time of the trajectory analysis at 9:00 a.m. and repeated the trajectory calculations every 1 hour until 4:00 p.m. (Figure S4 in the Supplement). In addition, a moving average window of 10 (i.e., $20 \mathrm{~s}$ ) was applied to the entire data set for VOC and OVOC species. Concentration baselines for each 2 -s point in the 20 -s smoothed data were calculated as the 5 th percentile concentration within a rolling window of 60 (i.e., 120 s), for which the urban background conditions were identified (Apte et al., 2017). We then computed the peak fraction (PF) parameter as 1 minus the ratio of the mean baseline value to the observed mean concentrations. The time series of the concentrations of common VOC and OVOC species shows significant plumes above the baseline for the on-road measurements (Figure S5 in the Supplement). PF values are used as a semi-quantitative indicator to show the contributions of the above-baseline concentrations to the observed concentrations of VOCs and OVOCs, which may represent the intensity of transient emission from local sources (e.g., vehicle exhaust).

\section{Results and Discussion}

\subsection{Spatial distribution of NR-PM2.5 and its components}

A significant spatial variability of the mass concentrations of NR-PM 2.5 and its chemical components is observed during the campaign. As described briefly by Liao et al. (2021), the mean ( \pm one standard deviation) mass concentration of $\mathrm{NR}_{-\mathrm{PM}} \mathrm{P}_{2.5}$ for non-haze days is $30.7 \pm 24.7 \mu \mathrm{g} \mathrm{m}^{-3}$, in which OA is the most abundant component that contributes to about $52 \%$ of the NR- 
$\mathrm{PM}_{2.5}$ mass. The mean mass concentration of NR-PM 2.5 for the haze day is $155.0 \pm 27.0 \mu \mathrm{g} \mathrm{m}^{-3}$, and nitrate becomes the most abundant component that contributes to about $48 \%$. Interestingly, the intracity spatial variations of the concentration and composition of NR-PM 2.5 are quite different under different pollution conditions.

Figure 1 shows the spatial distributions of the mass concentrations of organic and inorganic components in NR-PM 2.5 for the example noon cycles on typical clean and haze days. The coefficients of variation (CV) are listed in Table 1. Large spatial variabilities of the mass concentration and the composition of NR-PM 2.5 present in the clean-day measurements (Figure 1a). The mass concentration of NR-PM 2.5 ranges from 1.0 to $17 \mu \mathrm{g} \mathrm{m}^{-3}$ with a relatively high CV value of 0.75 . OA is the dominant component that explains the most variability of the NR-PM 2.5 mass. The spatial variations of the OA mass are largely attributed to POA. As shown in Fig. 1c, the mass fractions of POA factors such as HOA and COA show a large spatial heterogeneity with hot spots (mass fraction $>60 \%$ ) in various segments of the 4th Ring Road. These hot spots are plausibly contributed by exhaust plumes from on-road vehicles and nearby restaurants that have not yet well mixed with urban background air. Similarly, the measurements in Pittsburgh show a significant spatial heterogeneity of primary carbonaceous components such as HOA, COA, and BC and less spatial variabilities of OOAs (Gu et al., 2018).

Inorganic components show high CV values in mass fraction (Table 1), indicating a relatively greater spatial variability of inorganic composition compared with organic composition. As shown in Fig. 1b, ammonium is the predominant inorganic component in Zones NW and SW, while nitrate contributes most in Zone SE. The CV values for ammonium are the highest in both mass concentration and mass fraction. The molar ratio of $n_{\mathrm{NH}_{4}^{+}}:\left(2 \times n_{\mathrm{SO}_{4}^{2-}}+n_{\mathrm{NO}_{3}^{-}}\right)$range from $\sim 0$ to 1.0, suggesting a wide range of particle neutralization on the intracity scale under clean-day conditions in winter Beijing, which is perhaps driven by the difference in chemical processes and local emissions of precursors. In NCP, the aerosol mass can be sensitive to ammonia or nitric acid availability (Nenes et al., 2020). Traffic and agriculture (e.g., livestock) emissions are the main sources of ammonia in Beijing during the clean periods in winter (Sun et al., 2017; Pan et al., 2018). Traffic emissions depend on onroad vehicle type and volume and may vary greatly in the city. On the other hand, the concentrations of nitric acid depend on the concentrations of $\mathrm{NO}_{x}$ and hydroxyl radical $(\mathrm{OH})$ that are affected by local emissions and atmospheric oxidation and may also vary significantly in the city. Uniform solar radiation on the surface is not expected in the megacity because of the shades of buildings as well as cloud covers. Therefore, the spatial heterogeneity of inorganic composition reflects spatially different thermodynamic regimes in the megacity environment, which may challenge the development of further pollution control strategies as clean air action continues. For comparison, the inorganic components have less spatial variability in Pittsburgh than in Beijing (Gu et al., 2018), which may be explained by the greater emissions of ammonia and $\mathrm{NO}_{x}$ as well as higher $\mathrm{OH}$ concentrations in urban areas in China.

By contrast, relatively homogeneous spatial distributions of the mass concentration and composition of NR-PM 2.5 present under haze conditions (Figure 1d). The mass concentration of $\mathrm{NR}-\mathrm{PM}_{2.5}$ has a low CV value of 0.12 , and it is consistently higher in Zones NE and NW $\left(163.2 \pm 12.3 \mu \mathrm{g} \mathrm{m}^{-3}\right)$ than in Zones SE and SW $\left(138.8 \pm 16.9 \mu \mathrm{g} \mathrm{m}^{-3}\right)$. The mass fractions of 
inorganic (i.e., ammonium, sulfate, nitrate, chloride) and organic components (i.e., HOA, COA, and OOAs) are similar across the city $(\mathrm{CV}<0.35)$, although a few hot spots of COA exist (Figure 1f). The similar chemical composition across the city is consistent with the understanding of haze evolution in NCP during which regional transport becomes a main contributor to the $\mathrm{PM}$ pollution in Beijing. Over $60 \%$ of the $\mathrm{PM}_{1}$ and $\mathrm{PM}_{2.5}$ mass in Beijing can be contributed by regional transport during the winter haze episodes (Sun et al., 2014; Wu et al., 2021). The similar particle composition may suggest a chemical homogeneity on the megacity scale, and the north-south difference in mass concentration is perhaps driven by the differences in atmospheric dilution on the intracity scale (Sun et al., 2016; Chen et al., 2020). Moreover, the haze-day uniform spatial distribution of PM composition is similar to the observations in the metropolitan area of Zurich when thermal inversions occur over the Swiss plateau and secondary pollution is built up (Mohr et al., 2011), highlighting stagnant metrological conditions as one of the key drivers of the intracity chemical homogeneity. In addition, the large spatial variabilities of the mass concentration and composition of NR-PM $\mathrm{PM}_{2.5}$ present in all measurement cycles during the clean day, and the compositions of $\mathrm{NR}^{-\mathrm{PM}} 2.5$ on the 4th Ring Road are similar in each cycle during the haze day, not limited to the noon cycle.

\subsection{Spatial distribution of gaseous pollutants}

Figure 2 shows the spatial distributions of the mixing ratios of gaseous pollutants for the example noon cycles. The concentrations of $\mathrm{SO}_{2}$ are low (<10 ppbv) throughout the campaign (Figure 2a). During the clean day, the $\mathrm{SO}_{2}$ concentrations are low in the north and relatively high in the west of the 4th Ring Road, which is different from the distributions of the NR-

$\mathrm{PM}_{2.5}$ mass concentrations. The $\mathrm{SO}_{2}$ concentrations has a $\mathrm{CV}$ of 0.13 . The low spatial variability of $\mathrm{SO}_{2}$ may be explained by the predominant contribution of regional transport as a result of the relocation of steel industry and power plants out of Beijing and the ban of high emission vehicles from the road (Ge et al., 2018). Previous mobile measurements in Beijing captured specific transport events of $\mathrm{SO}_{2}$ from the south and found that the $\mathrm{SO}_{2}$ concentration decreased from Zone SE to Zone NW (Wang et al., 2011), which is consistent with our clean-day observations. During the haze day, the $\mathrm{SO}_{2}$ concentrations are lower than the concentrations observed during the clean day, which may be explained by the large conversion of gaseous $\mathrm{SO}_{2}$ to sulfate by photochemical and aqueous processes under winter-haze conditions (Wang et al., 2021b). The haze-day distribution of $\mathrm{SO}_{2}$ concentration is different from the clean-day distribution and has a greater $\mathrm{CV}$ value of 0.27 . The 12 -hour backward trajectories around the 4th Ring Road show that the air masses were mostly from the east in the morning, started shifting towards south at 12:00 p.m., and then were mainly originated from the south around 4:00 p.m. (Figure S4 in the Supplement). The spatial distribution of $\mathrm{SO}_{2}$ is therefore affected by the transport routes. Southwesterly, southeasterly, and easterly flux pathways have been recognized as typical regional transport routes to Beijing (Chang et al., 2019).

$\mathrm{CO}$ and NO are common gaseous pollutants emitted from combustion sources. The mean on-road concentrations of CO are $1.53 \pm 0.66 \mathrm{ppm}$ for non-haze days. For comparison, the concentrations of CO measured concurrently at the PKU roof site are $0.50 \pm 0.26 \mathrm{ppm}$ for non-haze days. The on-road concentrations are about three times greater than the urban background concentrations, explained by the direct contribution of vehicle emissions (Gentner et al., 2017). For NO, the concentrations measured at the PKU roof site are very low because of the $\mathrm{O}_{3}$ titration. The on-road concentrations are 1-2 orders of magnitude 
greater, which is mainly contributed by fleet integrated emissions. The clean-day spatial distribution of CO concentrations $(\mathrm{CV}=0.26)$ is quite homogeneous except a few hot spots in Zone SW (Figure 2b). The clean-day spatial distribution of NO concentrations $(\mathrm{CV}=0.22)$ is different from that of $\mathrm{CO}$ (Figure 2c), showing higher concentrations in Zone SE where the traffic volume is usually greater than in other Zones. One explanation for such differences between CO and NO may be much greater contributions of background concentrations and non-vehicular sources to CO. In addition, relatively slower response of instrument detection of CO and NO may smooth out some of the concentration variations. As shown in Fig. S6 in the Supplement, the on-road time series of $\mathrm{NO}_{2}$ concentrations shows more short-duration peaks than the time series of $\mathrm{CO}$ and NO concentrations. During the haze day, greater $\mathrm{CO}$ and NO concentrations present. The spatial distributions of $\mathrm{CO}, \mathrm{NO} \mathrm{SO}_{2}$, and NR-PM 2.5 concentrations all show relatively low concentrations in Zone SW. The greater haze-day concentrations and the similarity of spatial distributions of these pollutants are consistent with the large contribution of regional transport to urban air pollution and the stagnant meteorology condition during the haze episode.

The clean-day spatial distribution of $\mathrm{NO}_{2}$ concentrations is in general similar to that of NO, although more concentration hot spots exist (Figure $2 \mathrm{~d}$ ). The on-road $\mathrm{NO}_{2}$ are contributed by direct tailpipe $\mathrm{NO}_{2}$ emissions, secondary $\mathrm{NO}_{2}$ through on-road $\mathrm{NO}_{x}$ titration, and background $\mathrm{NO}_{2}$. The tailpipe $\mathrm{NO}_{2}$ emissions are small for LDGVs (National Stage III and above) (Wu et al., 2017). The urban background concentrations of $\mathrm{NO}_{2}$ measured at the PKU roof site on 18 November 2018 (clean day) are low at noon $(5.2 \pm 0.6 \mathrm{ppbv})$. The high on-road $\mathrm{NO}_{2}$ concentrations (16.8-94 ppbv) are therefore mainly contributed by the fast on-road $\mathrm{NO}_{x}$ titration, which is similar to the findings in North Carolina, U.S. (Yang et al., 2018). As shown in Fig. S7a in the Supplement, the clean-day on-road concentrations of $\mathrm{O}_{3}$ range from 3.2 to 15.4 ppbv, which are 3-4 times lower than the concentrations measured at the PKU roof site (40.0-44.5 ppbv). The spatial distribution of $\mathrm{O}_{3}$ concentration is opposite to that of NO, which is consistent with the titration effect. The more-frequent appearance of hot spots in the clean-day $\mathrm{NO}_{2}$ distribution is likely because of the faster detection of $\mathrm{NO}_{2}$ by cavity attenuated phase shift technique than the chemiluminescence detection of NO. During the haze day, the spatial distribution of $\mathrm{O}_{3}$ concentration is in general opposite to that of NO but shows much lower concentrations (i.e., a few ppbv) than during the clean day, which can be explained by the stronger titration effect with higher $\mathrm{NO}$ concentrations. However, the concentrations of $\mathrm{NO} \mathrm{NO}_{2}$, and $\mathrm{O}_{3}$ are all high in $\mathrm{Zone}$ NW. The backward trajectories suggest transport of air masses from the east and the south to Beijing. The high concentrations of air pollutants in Zone NW cannot be explained by regional transport and are perhaps related to local meteorological conditions affected by specific land surface conditions.

The spatial distributions of VOCs vary by species. LDGVs emit aromatic hydrocarbons (e.g., benzene, toluene, ethylbenzene, and xylenes), some oxygenated species (e.g., acetaldehyde), and so on (Gentner et al., 2017). As expected, the on-road concentrations of such primary VOC species are much greater than the concentrations measured at the urban and suburban sites in Beijing (Table S1 in the Supplement). Figure 2e-f shows the spatial distributions of benzene and toluene concentrations. During the clean day, both of the distributions show large spatial variabilities with high CV values (Table 1). Hot spots of concentration exist and are plausibly contributed by transient plumes of vehicle exhaust. Interestingly, the distributions of the 
hot spots for benzene and toluene are not the same, highlighting the difference in emissions from individual vehicles (Mo et al., 2016). The toluene-to-benzene concentration ratio (T/B) is widely used to differentiate the VOC sources (Song et al., 2021; and references therein). According to literature, traffic emissions have T/B ratios from 1 to 3 depending on vehicle type and fuel composition. Industry emissions have a wide range of T/B ratios (1.4 to 5.8). Solvent emissions may have high T/B ratio of $\sim 8$.8. Biomass burning emissions typically have a low ratio of $\sim 0.3$. During the clean day, most of the concentration hot spots for benzene and toluene corresponds to T/B ratios of 1.1-2.6, which is consistent with vehicle emissions (Fig. S7b in the Supplement). Some of the high T/B ratios (e.g., 2-3 in the south) are perhaps related to industry plumes. The T/B ratios for onroad background (not high-emitting plumes) are low (0.6-1.3), which may be explained by faster photochemical consumption of toluene than benzene. By contrast, the spatial variability for OVOCs $(\mathrm{CV} \sim 0.6)$ is much lower than that for hydrocarbons (Table 1), owing to their secondary nature because of the lack of localized sources in Beijing (Wang et al., 2021a). During the haze day, a remarkable enhancement of VOC concentrations is observed with mean enhancement ratios of 3.3-16.3 (e.g., 8.7 for benzene, 6.5 for toluene, 6.5 for $\mathrm{C}_{8}$-aromatics, 5.2 for methyl ethyl ketone, and 4.8 for propene) (Figure $\mathrm{S} 8$ in the Supplement). The spatial distributions of benzene and toluene show consistent high concentrations in Zones NW, SW, and SE (Figure 2e-f) but low T/B ratios in those segments that indicate aged air masses because biomass burning sources are limited during the campaign (Fig. S7b) (de Gouw et al., 2005). The spatial distributions of benzene and toluene are different from the distributions of other air pollutants under haze conditions, suggesting that the influence of regional transport may vary by species. Moreover, the haze-day spatial distributions of OVOC concentrations are quite homogeneous with relatively small CV values (i.e., 0.14 for $\Sigma$ (Aldehyde \& Ketones) and $\Sigma$ (Acids \& Anhydrides) in Table 1). The distribution of individual OVOCs is similar among species except for the OVOCs having 3-4 oxygen atoms in their formulae, which will be discussed further in Sect. 3.3. The calculated PF values suggest 30-40\% contributions of high-emitting plumes to the on-road concentrations of aromatic species during the clean day compared with 9-13\% during the haze day. For OVOCs (e.g., formic acid), the contribution of high-emitting plumes to the on-road concentrations are comparable for the clean and haze days (i.e., 6-13\%), owing to their secondary nature (Figure 3).

Photochemical oxidation can play an important role in concentrations of reactive organic species. The spatial-temporal variations of the concentrations of the detected VOCs and OVOCs measured during the non-haze and haze periods of the mobile campaign are shown in Figure 4. The concentrations of $\sum$ hydrocarbons (i.e., aromatics and alkenes) are the highest in the morning (8:00 a.m. to 10:00 a.m.) for both non-haze and haze periods, which may be explained by shallow boundary layer, rush-hour traffic emissions, and slow chemical removal (de Gouw et al., 2009). Their concentrations decrease first as the boundary layer develops, and then increase in the afternoon as the pollution accumulates in the boundary layer under non-haze conditions. By contrast, their concentrations keep decreasing during the day under haze conditions, and the greater day-time concentrations of $\sum$ hydrocarbons are plausibly driven by regional transport and stagnant meteorological conditions. Under non-haze conditions, the spatial variabilities of hydrocarbons vary significantly during the day. Their CV values are high in the morning and low in the afternoon. It is likely that the photochemistry and the better mixing conditions in the afternoon 
smooth out some of the spatial variabilities caused by on-road vehicle emissions (Mellouki et al., 2015; Karl et al., 2018). Under haze conditions, the spatial variability of hydrocarbons is slightly greater in the afternoon, which is probably because of the change of regional transport direction in the afternoon. The backward trajectories suggest that the air masses gradually shifted from eastern to southern during the haze day (Figure S4). For the two categories of OVOCs, the non-haze temporal variations are similar to that of hydrocarbons. Their CV values indicate much smaller spatial variabilities of OVOCs in the morning rush hour (8:00 a.m. to 10:00 a.m.) than that of hydrocarbons. This is consistent with previous source apportionment results that secondary production is the main contributor of most OVOCs in Beijing (Wang et al., 2021a). As the photochemical production proceeds during the day, the spatial variabilities of OVOCs increase and then decrease, similar to that of hydrocarbons. On the other hand, the haze-day temporal and spatial variations of OVOCs are all similar to that of hydrocarbons $(\mathrm{CV}<0.36)$, corresponding to the influence of regional transport.

\subsection{Chemical heterogeneity under haze conditions}

Figure 5 shows the correlation heatmaps of the concentrations of VOCs and OVOCs measured during the clean day and haze day for all measurement cycles on the 4th Ring Road of Beijing. Only primary hydrocarbons show good correlations with each other during the clean day (Figure 5a). This is consistent with the predominant contribution of traffic emissions to the on-road concentrations. Secondary species like OVOCs and $\mathrm{PM}_{2.5}$ are more regional and do not correlate with these primary hydrocarbons (Figure S9a in the Supplement). By contrast, the haze-day heatmaps show significantly different patterns (Figure $5 \mathrm{~b}$ and Figure S9b in the Supplement). Primary hydrocarbons not only correlate well with each other (Pearson's $r>0.7, \alpha=$ 0.01) but also show good positive correlations with many less-oxygenated OVOCs (e.g., aldehydes and ketones with 1-2 oxygen atoms in their formulae (Table S1). These OVOCs may be contributed by both primary and secondary sources, and they can be formed and accumulated during the regional transport. The NR-PM 2.5 components also correlate with these VOCs and OVOCs (Figure S9b). Such good spatial-temporal correlations are consistent with the predominant contribution of regional transport to hydrocarbons, less-oxygenated OVOCs, and $\mathrm{PM}_{2.5}$.

Interestingly, more oxygenated OVOCs (e.g., anhydrides and acids with 2-4 oxygen atoms in their formulae) that are mainly contributed by secondary sources show good positive correlations with each other $(r>0.7, \alpha=0.01)$ and moderately negative correlations with hydrocarbons and less-oxygenated OVOCs as well as the NR-PM 2.5 components. These species include $\mathrm{CH}_{2} \mathrm{O}_{2}$ (tentatively assigned as formic acid), $\mathrm{C}_{2} \mathrm{H}_{4} \mathrm{O}_{3}, \mathrm{C}_{3} \mathrm{H}_{4} \mathrm{O}_{3}, \mathrm{C}_{4} \mathrm{H}_{4} \mathrm{O}_{4}, \mathrm{C}_{4} \mathrm{H}_{4} \mathrm{O}_{3}, \mathrm{C}_{5} \mathrm{H}_{4} \mathrm{O}_{3}$, and $\mathrm{C}_{5} \mathrm{H}_{4} \mathrm{O}_{2}$. The spatial-temporal correlations for these more oxygenated OVOCs may be explained by a homogeneous photochemical production on the intracity scale. High oxidation capacity in winter in NCP has been reported (Lu et al., 2019a; Slater et al., 2020). Secondary OVOCs are formed and accumulated along the transport route. Regional transport leads to relatively uniform spatial distributions of these species during the haze day (Figure 4). With a rather uniform distribution of hydroxyl radical which likely happens under winter haze conditions because of the thick cloud cover and increased particle scattering, the formation of more-oxygenated OVOCs from less-oxygenated OVOCs can be relatively homogeneous in the city. Although these more-oxygenated OVOCs 
may partition to the particle phase, the gas-to-particle partitioning are not expected to affect much the spatial variability of the more-oxygenated OVOCs because similar chemical composition of $\mathrm{PM}_{2.5}$ present on the intracity scale under haze conditions. The secondary production and potential gas-to-particle partitioning explain negative correlations of the more-oxygenated OVOCs with their precursors (hydrocarbon and less-oxygenated OVOCs) and $\mathrm{PM}_{2.5}$. Moreover, the gas-particle repartitioning caused by temperature difference may affect the distribution of more-oxygenated OVOCs. This effect is however expected to be minor considering the OA loadings, vapor pressures of these more-oxygenated OVOCs, and possible temperature elevation of $1-3{ }^{\circ} \mathrm{C}$ for the megacity (Chen et al., 2020; Wang et al., 2020; Yang et al., 2013). Peroxyacetyl nitrate (PAN) is more sensitive to temperature and less stable than the other more-oxygenated OVOCs (Seinfeld and Pandis, 2016), which may explain lower correlation coefficient of its fragment $\left(\mathrm{C}_{2} \mathrm{H}_{4} \mathrm{O}_{3}\right)$ in Fig. 5 b.

\section{Conclusions}

In this study, we conducted on-road mobile measurements of air pollutants including NR-PM 2.5 and its components, gaseous pollutants, VOCs, and OVOCs under different pollution levels in winter in Beijing. During the clean periods, large spatial variabilities of the pollutants were observed, which can be largely attributed to the influence of localized sources. In particular, the inorganic composition of NR-PM 2.5 vary greatly, indicating a wide range of particle neutralization on the intracity scale under less-polluted conditions in winter Beijing. For OA, the spatial variability is mainly driven by local HOA and COA emissions. The spatial variations of regular gas pollutants are relatively smaller than those of the $\mathrm{PM}_{2.5}$ components. The spatial distributions of the concentrations of VOCs and OVOCs vary by species. Detected hydrocarbons (i.e. mostly aromatic species) are affected by on-road vehicle emissions, and thus show large spatial variabilities during the clean periods. The large spatial heterogeneity of the particle composition and VOCs may challenge the development of future pollution control strategies as clean air actions continue. The results also indicate different human exposures to particles and gaseous pollutants on the intracity scale, which requires fine-resolution models to evaluate. Moreover, our results suggest about 30-40\% contributions of high-emitting plumes to the on-road concentrations of aromatic species during the clean periods compared with 9-13\% during the haze periods. Under haze conditions, stagnant weather and predominantly contributions from regional transport largely reduce the spatial variabilities of particulate and gaseous pollutants in the city. More-oxygenated OVOCs show good positive correlation among themselves and moderate negative correlations with hydrocarbons, less-oxygenated OVOCs, and $\mathrm{PM}_{2.5}$ components, suggesting a homogeneous photochemical production on the intracity scale. This chemical homogeneity may lead to local production of semivolatile oxidation products that may enhance the SOA production under winter haze conditions in the megacity.

Data availability. Data presented in this manuscript are available upon request to the corresponding author. 
Author contributions. QC designed the study. KL conducted the experiments and data analysis with the help of QC, RK, YL,

YZ, XC, TJ, XL, SC, and GH. QC, RK, and KL wrote the manuscript.

Competing interests. The authors declare no competing financial interests.

Acknowledgements. This work was supported by the National Natural Science Foundation of China (91544107, 41875165, 41961134034, and 51861135102) and the 111 Project of Urban Air Pollution and Health Effects (B20009). The authors thank

Theodore K. Koenig for helpful discussions.

\section{References}

325 Apte, J. S., Messier, K. P., Gani, S., Brauer, M., Kirchstetter, T. W., Lunden, M. M., Marshall, J. D., Portier, C. J., Vermeulen, R. C. H., and Hamburg, S. P.: High-resolution air pollution mapping with Google street view cars: Exploiting big data, Environ. Sci. Technol., 51, 6999-7008, https://doi.org/10.1021/acs.est.7b00891, 2017.

Bell, M. L., Peng, R. D., and Dominici, F.: The exposure-response curve for ozone and risk of mortality and the adequacy of current ozone regulations, Environ. Health Perspect., 114, 532-536, https://doi.org/10.1289/ehp.8816, 2006.

330 Canagaratna, M. R., Jayne, J. T., Jimenez, J. L., Allan, J. D., Alfarra, M. R., Zhang, Q., Onasch, T. B., Drewnick, F., Coe, H., Middlebrook, A., Delia, A., Williams, L. R., Trimborn, A. M., Northway, M. J., DeCarlo, P. F., Kolb, C. E., Davidovits, P., and Worsnop, D. R.: Chemical and microphysical characterization of ambient aerosols with the aerodyne aerosol mass spectrometer, Mass Spectrom. Rev., 26, 185-222, https://doi.org/10.1002/mas.20115, 2007.

Chang, X., Wang, S. X., Zhao, B., Xing, J., Liu, X. X., Wei, L., Song, Y., Wu, W. J., Cai, S. Y., Zheng, H. T., Ding, D., and Zheng, M.: Contributions of inter-city and regional transport to PM2.5 concentrations in the Beijing-Tianjin-Hebei region and its implications on regional joint air pollution control, Sci. Total Environ., 660, 1191-1200,

https://doi.org/10.1016/j.scitotenv.2018.12.474, 2019.

Chen, Y., Cai, J., Wang, Z. C., Peng, C., Yao, X. J., Tian, M., Han, Y. Q., Shi, G. M., Shi, Z. B., Liu, Y., Yang, X., Zheng, M., Zhu, T., He, K. B., Zhang, Q., and Yang, F. M.: Simultaneous measurements of urban and rural particles in Beijing -

340 Part 1: Chemical composition and mixing state, Atmos. Chem. Phys., 20, 9231-9247, https://doi.org/10.5194/acp-20-9231$2020,2020$.

Cheng, X., Chen, Q., Li, Y., Huang, G., Liu, Y., Lu, S., Zheng, Y., Qiu, W., Lu, K., Qiu, X., Bianchi, F., Yan, C., Yuan, B., Shao, M., Wang, Z., Canagaratna, M. R., Zhu, T., Wu, Y., and Zeng, L.: Secondary production of gaseous nitrated phenols in polluted urban environments, Environ. Sci. Technol., https://doi.org/10.1021/acs.est.0c07988, 2021.

345 de Gouw, J. A., Middlebrook, A. M., Warneke, C., Goldan, P. D., Kuster, W. C., Roberts, J. M., Fehsenfeld, F. C., Worsnop, D. R., Canagaratna, M. R., Pszenny, A. A. P., Keene, W. C., Marchewka, M., Bertman, S. B., and Bates, T. S.: Budget of organic carbon in a polluted atmosphere: Results from the New England Air Quality Study in 2002, J. Geophys. Res-Atmos., 110, 22, https://doi.org/10.1029/2004jd005623, 2005. 
de Gouw, J. A., Welsh-Bon, D., Warneke, C., Kuster, W. C., Alexander, L., Baker, A. K., Beyersdorf, A. J., Blake, D. R., Canagaratna, M., Celada, A. T., Huey, L. G., Junkermann, W., Onasch, T. B., Salcido, A., Sjostedt, S. J., Sullivan, A. P., Tanner, D. J., Vargas, O., Weber, R. J., Worsnop, D. R., Yu, X. Y., and Zaveri, R.: Emission and chemistry of organic carbon in the gas and aerosol phase at a sub-urban site near Mexico City in March 2006 during the MILAGRO study, Atmos. Chem. Phys., 9, 3425-3442, https://doi.org/10.5194/acp-9-3425-2009, 2009.

Duan, J., Huang, R. J., Li, Y. J., Chen, Q., Zheng, Y., Chen, Y., Lin, C. S., Ni, H. Y., Wang, M., Ovadnevaite, J., Ceburnis, D., Chen, C. Y., Worsnop, D. R., Hoffmann, T., O'Dowd, C., and Cao, J. J.: Summertime and wintertime atmospheric processes of secondary aerosol in Beijing, Atmos. Chem. Phys., 20, 3793-3807, https://doi.org/10.5194/acp-20-3793-2020, 2020.

Elser, M., Bozzetti, C., El-Haddad, I., Maasikmets, M., Teinemaa, E., Richter, R., Wolf, R., Slowik, J. G., Baltensperger, U., and Prevot, A. S. H.: Urban increments of gaseous and aerosol pollutants and their sources using mobile aerosol mass spectrometry measurements, Atmos. Chem. Phys., 16, 7117-7134, https://doi.org/10.5194/acp-16-7117-2016, 2016.

Ge, B. Z., Wang, Z. F., Lin, W. L., Xu, X. B., Li, J., Ji, D. S., and Ma, Z. Q.: Air pollution over the North China Plain and its implication of regional transport: A new sight from the observed evidences, Environ. Pollut., 234, 29-38, https://doi.org/10.1016/j.envpol.2017.10.084, 2018.

Gentner, D. R., Jathar, S. H., Gordon, T. D., Bahreini, R., Day, D. A., El Haddad, I., Hayes, P. L., Pieber, S. M., Platt, S. M., de Gouw, J., Goldstein, A. H., Harley, R. A., Jimenez, J. L., Prevot, A. S. H., and Robinson, A. L.: Review of urban secondary organic aerosol formation from gasoline and diesel motor vehicle emissions, Environ. Sci. Technol., 51, 10741093, https://doi.org/10.1021/acs.est.6b04509, 2017.

Gu, P. S., Li, H., Ye, Q., Robinson, E. S., Apte, J. S., Robinson, A. L., and Presto, A. A.: Intracity variability of particulate matter exposure is driven by carbonaceous sources and correlated with land-use variables, Environ. Sci. Technol., 52, 1154511554, https://doi.org/10.1021/acs.est.8b03833, 2018.

Guo, H., Ling, Z. H., Cheng, H. R., Simpson, I. J., Lyu, X. P., Wang, X. M., Shao, M., Lu, H. X., Ayoko, G., Zhang, Y. L., Saunders, S. M., Lam, S. H. M., Wang, J. L., and Blake, D. R.: Tropospheric volatile organic compounds in China, Sci. Total Environ., 574, 1021-1043, https://doi.org/10.1016/j.scitotenv.2016.09.116, 2017.

Huang, G. C., Liu, Y., Shao, M., Li, Y., Chen, Q., Zheng, Y., Wu, Z. J., Liu, Y. C., Wu, Y. S., Hu, M., Li, X., Lu, S. H., Wang, C. J., Liu, J. Y., Zheng, M., and Zhu, T.: Potentially important contribution of gas-phase oxidation of naphthalene and methylnaphthalene to secondary organic aerosol during haze events in Beijing, Environ. Sci. Technol., 53, 1235-1244, https://doi.org/10.1021/acs.est.8b04523, 2019.

Huang, R. J., Zhang, Y. L., Bozzetti, C., Ho, K. F., Cao, J. J., Han, Y. M., Daellenbach, K. R., Slowik, J. G., Platt, S. M., Canonaco, F., Zotter, P., Wolf, R., Pieber, S. M., Bruns, E. A., Crippa, M., Ciarelli, G., Piazzalunga, A., Schwikowski, M., Abbaszade, G., Schnelle-Kreis, J., Zimmermann, R., An, Z. S., Szidat, S., Baltensperger, U., El Haddad, I., and Prevot, A. S. H.: High secondary aerosol contribution to particulate pollution during haze events in China, Nature, 514, 218-222, https://doi.org/10.1038/nature13774, 2014.

Karl, T., Striednig, M., Graus, M., Hammerle, A., and Wohlfahrt, G.: Urban flux measurements reveal a large pool of oxygenated volatile organic compound emissions, Proc. Natl. Acad. Sci. U. S. A., 115, 1186-1191, https://doi.org/10.1073/pnas.1714715115, 2018.

Khuzestani, R. B., Schauer, J. J., Wei, Y. J., Zhang, L. L., Cai, T. Q., Zhang, Y., and Zhang, Y. X.: Quantification of the sources of long-range transport of PM2.5 pollution in the Ordos region, Inner Mongolia, China, Environ. Pollut., 229, 10191031, https://doi.org/10.1016/j.envpol.2017.07.093, 2017. 
Kolb, C. E., Herndon, S. C., McManus, B., Shorter, J. H., Zahniser, M. S., Nelson, D. D., Jayne, J. T., Canagaratna, M. R., and Worsnop, D. R.: Mobile laboratory with rapid response instruments for real-time measurements of urban and regional trace gas and particulate distributions and emission source characteristics, Environ. Sci. Technol., 38, 5694-5703, https://doi.org/10.1021/es030718p, 2004.

Lei, L., Zhou, W., Chen, C., He, Y., Li, Z. J., Sun, J. X., Tang, X., Fu, P. Q., Wang, Z. F., and Sun, Y. L.: Long-term characterization of aerosol chemistry in cold season from 2013 to 2020 in Beijing, China, Environ. Pollut., 268, 9 , https://doi.org/10.1016/j.envpol.2020.115952, 2021.

Li, J., Wu, R. R., Li, Y. Q., Hao, Y. F., Xie, S. D., and Zeng, L. M.: Effects of rigorous emission controls on reducing ambient volatile organic compounds in Beijing, China, Sci. Total Environ., 557, 531-541, https://doi.org/10.1016/j.scitotenv.2016.03.140, 2016.

Li, Y. J., Sun, Y., Zhang, Q., Li, X., Li, M., Zhou, Z., and Chan, C. K.: Real-time chemical characterization of atmospheric particulate matter in China: A review, Atmos. Environ., 158, 270-304, https://doi.org/10.1016/j.atmosenv.2017.02.027, 2017.

Liang, Q., Bao, X., Sun, Q., Zhang, Q., Zou, X., Huang, C., Shen, C., and Chu, Y.: Imaging VOC distribution in cities and tracing VOC emission sources with a novel mobile proton transfer reaction mass spectrometer, Environ. Pollut., 265, https://doi.org/10.1016/j.envpol.2020.114628, 2020.

Liao, K., Chen, Q., Liu, Y., Li, Y. J., Lambe, A. T., Zhu, T., Huang, R.-J., Zheng, Y., Cheng, X., Miao, R., Huang, G., Khuzestani, R. B., and Jia, T.: Secondary organic aerosol formation of fleet vehicle emissions in China: Potential seasonality of spatial distributions, Environ. Sci. Technol., https://doi.org/10.1021/acs.est.0c08591, 2021.

Liu, J., Han, Y. Q., Tang, X., Zhu, J., and Zhu, T.: Estimating adult mortality attributable to PM2.5 exposure in China with assimilated PM2.5 concentrations based on a ground monitoring network, Sci. Total Environ., 568, 1253-1262, https://doi.org/10.1016/j.scitotenv.2016.05.165, 2016.

Lu, K. D., Fuchs, H., Hofzumahaus, A., Tan, Z. F., Wang, H. C., Zhang, L., Schmitt, S. H., Rohrer, F., Bohn, B., Broch, S., Dong, H. B., Gkatzelis, G. I., Hohaus, T., Holland, F., Li, X., Liu, Y., Liu, Y. H., Ma, X. F., Novelli, A., Schlag, P., Shao, M., Wu, Y. S., Wu, Z. J., Zeng, L. M., Hu, M., Kiendler-Scharr, A., Wahner, A., and Zhang, Y. H.: Fast photochemistry in wintertime haze: Consequences for pollution mitigation strategies, Environ. Sci. Technol., 53, 10676-10684, https://doi.org/10.1021/acs.est.9b02422, 2019a.

Lu, K. D., Guo, S., Tan, Z. F., Wang, H. C., Shang, D. J., Liu, Y. H., Li, X., Wu, Z. J., Hu, M., and Zhang, Y. H.: Exploring atmospheric free-radical chemistry in China: the self-cleansing capacity and the formation of secondary air pollution, Natl. Sci. Rev., 6, 579-594, https://doi.org/10.1093/nsr/nwy073, 2019b.

Mellouki, A., Wallington, T. J., and Chen, J.: Atmospheric chemistry of oxygenated volatile organic compounds: Impacts on air quality and climate, Chem. Rev., 115, 3984-4014, https://doi.org/10.1021/cr500549n, 2015.

Mo, Z. W., Huang, S., Yuan, B., Pei, C. L., Song, Q. C., Qi, J. P., Wang, M., Wang, B. L., Wang, C., Li, M., Zhang, Q., and Shao, M.: Deriving emission fluxes of volatile organic compounds from tower observation in the Pearl River Delta, China, Sci. Total Environ., 741, 9, https://doi.org/10.1016/j.scitotenv.2020.139763, 2020.

Mo, Z. W., Shao, M., and Lu, S. H.: Compilation of a source profile database for hydrocarbon and OVOC emissions in China, Atmos. Environ., 143, 209-217, https://doi.org/10.1016/j.atmosenv.2016.08.025, 2016. 
Mohr, C., Richter, R., DeCarlo, P. F., Prevot, A. S. H., and Baltensperger, U.: Spatial variation of chemical composition and sources of submicron aerosol in Zurich during wintertime using mobile aerosol mass spectrometer data, Atmos. Chem. Phys., 11, 7465-7482, https://doi.org/10.5194/acp-11-7465-2011, 2011.

Mozaffar, A., and Zhang, Y. L.: Atmospheric Volatile Organic Compounds (VOCs) in China: a Review, Curr. Pollut. Rep., 6, 250-263, https://doi.org/10.1007/s40726-020-00149-1, 2020.

Nenes, A., Pandis, S. N., Weber, R. J., and Russell, A.: Aerosol pH and liquid water content determine when particulate matter is sensitive to ammonia and nitrate availability, Atmos. Chem. Phys., 20, 3249-3258, https://doi.org/10.5194/acp-203249-2020, 2020.

Pan, Y. P., Tian, S. L., Liu, D. W., Fang, Y. T., Zhu, X. Y., Gao, M., Wentworth, G. R., Michalski, G., Huang, X. J., and Wang, Y. S.: Source apportionment of aerosol ammonium in an ammonia-rich atmosphere: An isotopic study of summer clean and hazy days in urban Beijing, J. Geophys. Res-Atmos., 123, 5681-5689, https://doi.org/10.1029/2017jd028095, 2018 .

Quan, J. N., and Jia, X. C.: Review of aircraft measurements over China: aerosol, atmospheric photochemistry, and cloud, Atmos. Res., 243, 14, https://doi.org/10.1016/j.atmosres.2020.104972, 2020.

Seinfeld, J. H., and Pandis, S. N.: Atmospheric Chemistry and Physics: From Air Pollution to Climate Change, Third Edition, John Wiley \& Sons, Inc., Hoboken, New Jersey, 2016.

Slater, E. J., Whalley, L. K., Woodward-Massey, R., Ye, C. X., Lee, J. D., Squires, F., Hopkins, J. R., Dunmore, R. E., Shaw, M., Hamilton, J. F., Lewis, A. C., Crilley, L. R., Kramer, L., Bloss, W., Vu, T., Sun, Y. L., Xu, W. Q., Yue, S. Y., Ren, L. J., Acton, W. J. F., Hewitt, C. N., Wang, X. M., Fu, P. Q., and Heard, D. E.: Elevated levels of OH observed in haze events during wintertime in central Beijing, Atmos. Chem. Phys., 20, 14847-14871, https://doi.org/10.5194/acp-20-14847$2020,2020$.

Song, M. D., Li, X., Yang, S. D., Yu, X. N., Zhou, S. X., Yang, Y. M., Chen, S. Y., Dong, H. B., Liao, K. R., Chen, Q., Lu, K. D., Zhang, N. N., Cao, J. J., Zeng, L. M., and Zhang, Y. H.: Spatiotemporal variation, sources, and secondary transformation potential of volatile organic compounds in Xi'an, China, Atmos. Chem. Phys., 21, 4939-4958, https://doi.org/10.5194/acp-21-4939-2021, 2021.

Stein, A. F., Draxler, R. R., Rolph, G. D., Stunder, B. J. B., Cohen, M. D., and Ngan, F.: NOAA'S hysplit atmospheric transport and dispersion modeling system, Bull. Amer. Meteorol. Soc., 96, 2059-2077, https://doi.org/10.1175/bams-d-14$00110.1,2015$.

Sun, J., Wang, Y. S., Wu, F. K., Tang, G. Q., Wang, L. L., Wang, Y. H., and Yang, Y.: Vertical characteristics of VOCs in the lower troposphere over the North China Plain during pollution periods, Environ. Pollut., 236, 907-915, https://doi.org/10.1016/j.envpol.2017.10.051, 2018.

Sun, K., Tao, L., Miller, D. J., Pan, D., Golston, L. M., Zondlo, M. A., Griffin, R. J., Wallace, H. W., Leong, Y. J., Yang, M. M., Zhang, Y., Mauzerall, D. L., and Zhu, T.: Vehicle emissions as an important urban ammonia source in the United States and China, Environ. Sci. Technol., 51, 2472-2481, https://doi.org/10.1021/acs.est.6b02805, 2017.

460 Sun, Y. L., Chen, C., Zhang, Y. J., Xu, W. Q., Zhou, L. B., Cheng, X. L., Zheng, H. T., Ji, D. S., Li, J., Tang, X., Fu, P. Q., and Wang, Z. F.: Rapid formation and evolution of an extreme haze episode in Northern China during winter 2015 , Sci. Rep., 6, 9, https://doi.org/10.1038/srep27151, 2016. 
Sun, Y. L., Jiang, Q., Wang, Z. F., Fu, P. Q., Li, J., Yang, T., and Yin, Y.: Investigation of the sources and evolution processes of severe haze pollution in Beijing in January 2013, J. Geophys. Res-Atmos., 119, 4380-4398, https://doi.org/10.1002/2014jd021641, 2014.

Tan, Y., Lipsky, E. M., Saleh, R., Robinson, A. L., and Presto, A. A.: Characterizing the spatial variation of air pollutants and the contributions of high emitting vehicles in Pittsburgh, PA, Environ. Sci. Technol., 48, 14186-14194, https://doi.org/10.1021/es5034074, 2014.

Wang, L. W., Slowik, J. G., Tong, Y. D., Duan, J., Gu, Y. F., Rai, P., Qi, L., Stefenelli, G., Baltensperger, U., Huang, R. J., Cao, J. J., and Prevot, A. S. H.: Characteristics of wintertime VOCs in urban Beijing: Composition and source apportionment, Atmos. Environ-X, 9, 12, https://doi.org/10.1016/j.aeaoa.2020.100100, 2021a.

Wang, M., Zhu, T., Zhang, J. P., Zhang, Q. H., Lin, W. W., Li, Y., and Wang, Z. F.: Using a mobile laboratory to characterize the distribution and transport of sulfur dioxide in and around Beijing, Atmos. Chem. Phys., 11, 11631-11645, https://doi.org/10.5194/acp-11-11631-2011, 2011.

475 Wang, M., Zhu, T., Zheng, J., Zhang, R. Y., Zhang, S. Q., Xie, X. X., Han, Y. Q., and Li, Y.: Use of a mobile laboratory to evaluate changes in on-road air pollutants during the Beijing 2008 Summer Olympics, Atmos. Chem. Phys., 9, 8247-8263, https://doi.org/10.5194/acp-9-8247-2009, 2009.

Wang, Q., Zhang, C., Ren, C., Hang, J., and Li, Y. G.: Urban heat island circulations over the Beijing-Tianjin region under calm and fair conditions, Build. Environ., 180, 12, https://doi.org/10.1016/j.buildenv.2020.107063, 2020.

480 Wang, T., Xue, L. K., Brimblecombe, P., Lam, Y. F., Li, L., and Zhang, L.: Ozone pollution in China: A review of concentrations, meteorological influences, chemical precursors, and effects, Sci. Total Environ., 575, 1582-1596, https://doi.org/10.1016/j.scitotenv.2016.10.081, 2017.

Wang, W. G., Liu, M. Y., Wang, T. T., Song, Y., Zhou, L., Cao, J. J., Hu, J. N., Tang, G. G., Chen, Z., Li, Z. J., Xu, Z. Y., Peng, C., Lian, C. F., Chen, Y., Pan, Y. P., Zhang, Y. H., Sun, Y. L., Li, W. J., Zhu, T., Tian, H. Z., and Ge, M. F.: Sulfate formation is dominated by manganese-catalyzed oxidation of $\mathrm{SO} 2$ on aerosol surfaces during haze events, Nat. Commun., 12, 10, https://doi.org/10.1038/s41467-021-22091-6, 2021b.

Wang, X., Cai, Y. J., Wang, J. J., and Zhao, Y. F.: Concentration monitoring of volatile organic compounds and ozone in Xi'an based on PTR-TOF-MS and differential absorption lidar, Atmos. Environ., 245, 12, https://doi.org/10.1016/j.atmosenv.2020.118045, 2021c.

490 Wu, F. C., Xie, P. H., Li, A., Mou, F. S., Chen, H., Zhu, Y., Zhu, T., Liu, J. G., and Liu, W. Q.: Investigations of temporal and spatial distribution of precursors $\mathrm{SO} 2$ and NO2 vertical columns in the North China Plain using mobile DOAS, Atmos. Chem. Phys., 18, 1535-1554, https://doi.org/10.5194/acp-18-1535-2018, 2018.

Wu, J. R., Bei, N. F., Wang, Y., Li, X., Liu, S. X., Liu, L., Wang, R. N., Yu, J. Y., Le, T. H., Zuo, M., Shen, Z. X., Cao, J. J., Tie, X. X., and Li, G. H.: Insights into particulate matter pollution in the North China Plain during wintertime: local contribution or regional transport?, Atmos. Chem. Phys., 21, 2229-2249, https://doi.org/10.5194/acp-21-2229-2021, 2021.

Wu, Y., Zhang, S. J., Hao, J. M., Liu, H., Wu, X. M., Hu, J. N., Walsh, M. P., Wallington, T. J., Zhang, K. M., and Stevanovic, S.: On-road vehicle emissions and their control in China: A review and outlook, Sci. Total Environ., 574, 332349, https://doi.org/10.1016/j.scitotenv.2016.09.040, 2017. 
Yang, B., Zhang, K. M., Xu, W. D., Zhang, S. J., Batterman, S., Baldauf, R. W., Deshmukh, P., Snow, R., Wu, Y., Zhang, Q., Li, Z. H., and Wu, X.: On-road chemical transformation as an important mechanism of NO2 formation, Environ. Sci. Technol., 52, 4574-4582, https://doi.org/10.1021/acs.est.7b05648, 2018.

Yang, P., Ren, G. Y., and Liu, W. D.: Spatial and temporal characteristics of Beijing urban heat island intensity, J. Appl. Meteorol. Climatol., 52, 1803-1816, https://doi.org/10.1175/jamc-d-12-0125.1, 2013.

Ye, Q., Gu, P., Li, H. Z., Robinson, E. S., Lipsky, E., Kaltsonoudis, C., Lee, A. K. Y., Apte, J. S., Robinson, A. L., Sullivan, R. C., Presto, A. A., and Donahue, N. M.: Spatial variability of sources and mixing state of atmospheric particles in a metropolitan area, Environ. Sci. Technol., 52, 6807-6815, https://doi.org/10.1021/acs.est.8b01011, 2018.

Zhang, Q., Zheng, Y. X., Tong, D., Shao, M., Wang, S. X., Zhang, Y. H., Xu, X. D., Wang, J. N., He, H., Liu, W. Q., Ding, Y. H., Lei, Y., Li, J. H., Wang, Z. F., Zhang, X. Y., Wang, Y. S., Cheng, J., Liu, Y., Shi, Q. R., Yan, L., Geng, G. N., Hong, C. P., Li, M., Liu, F., Zheng, B., Cao, J. J., Ding, A. J., Gao, J., Fu, Q. Y., Huo, J. T., Liu, B. X., Liu, Z. R., Yang, F. M., He, 510 K. B., and Hao, J. M.: Drivers of improved PM2.5 air quality in China from 2013 to 2017, Proc. Natl. Acad. Sci. U. S. A., 116, 24463-24469, https://doi.org/10.1073/pnas.1907956116, 2019.

Zheng, Y., Cheng, X., Liao, K. R., Li, Y. W., Li, Y. J., Hu, W. W., Liu, Y., Zhu, T., Chen, S. Y., Zeng, L. M., Worsnop, D., Chen, Q., and Huang, R. J.: Characterization of anthropogenic organic aerosols by TOF-ACSM with the new capture vaporizer, Atmos. Meas. Tech., 13, 2457-2472, https://doi.org/10.5194/amt-13-2457-2020, 2020.

515 Zhou, W., Sun, Y. L., Xu, W. Q., Zhao, X. J., Wang, Q. Q., Tang, G. Q., Zhou, L. B., Chen, C., Du, W., Zhao, J., Xie, C. H., Fu, P. Q., and Wang, Z. F.: Vertical characterization of aerosol particle composition in Beijing, China: Insights from 3month measurements with two aerosol mass spectrometers, J. Geophys. Res-Atmos., 123, 13016-13029, https://doi.org/10.1029/2018jd029337, 2018.

Zhu, Y., Zhang, J. P., Wang, J. X., Chen, W. Y., Han, Y. Q., Ye, C. X., Li, Y. R., Liu, J., Zeng, L. M., Wu, Y. S., Wang, X. F., Wang, W. X., Chen, J. M., and Zhu, T.: Distribution and sources of air pollutants in the North China Plain based on onroad mobile measurements, Atmos. Chem. Phys., 16, 12551-12565, https://doi.org/10.5194/acp-16-12551-2016, 2016. 


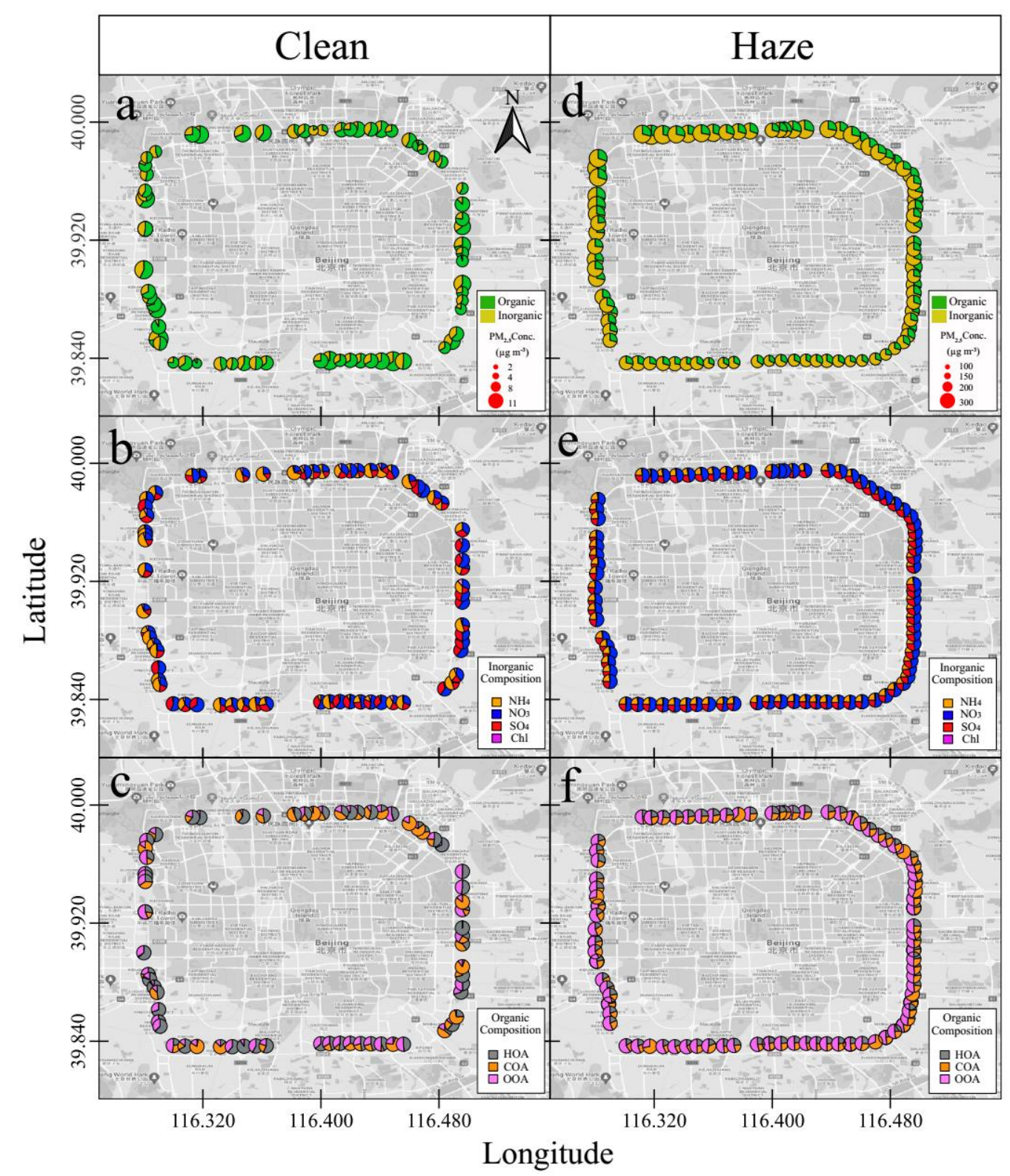

Figure 1. Spatial distribution of (a, d) the mass concentration $\left(\mu \mathrm{g} \mathrm{m}^{-3}\right),(\mathrm{b}, \mathrm{e})$ the inorganic composition, and (c, f) the organic composition of NR-PM 2.5 measured during the noon cycles from 11:00 AM to 12:30 PM for the clean day on 18 November 2018 and the haze day on 14 November 2018 in Beijing (source: (C) Google Maps 2020). The size of the pies for inorganic and organic composition is the same and does not correspond to the mass concentrations of components. The organic composition is obtained from the PMF analysis, in which OOA represents the sum of the three OOA factors. 


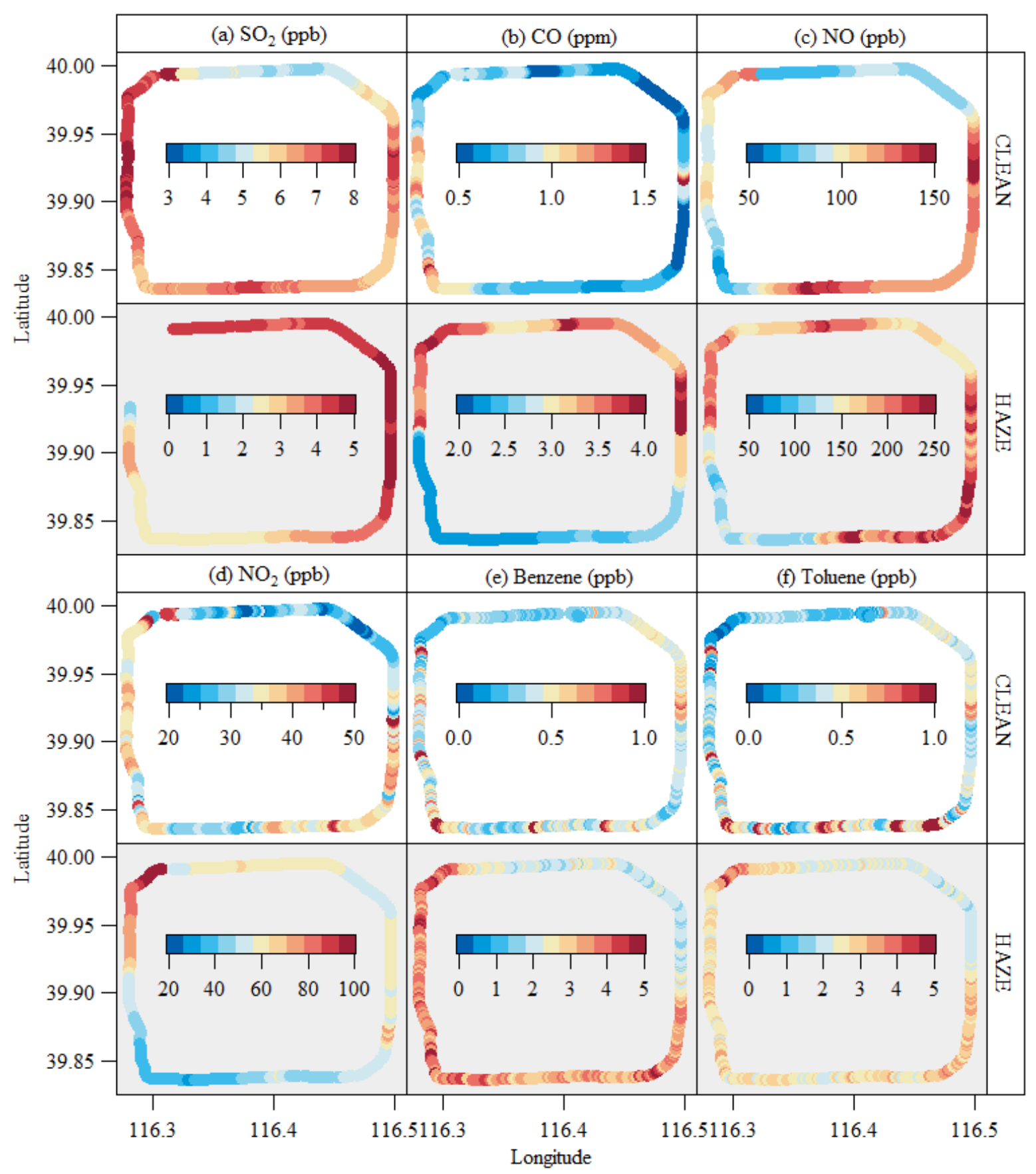

Figure 2. Spatial distributions of gaseous pollutants including (a) $\mathrm{SO}_{2}$, (b) $\mathrm{CO}$, (c) $\mathrm{NO}$, (d) $\mathrm{NO}_{2}$, (e) benzene, and (f) toluene measured during the noon cycles from 11:00 AM to 12:30 PM for the clean day on 18 November 2018 and the haze day on 14 November 2018. 


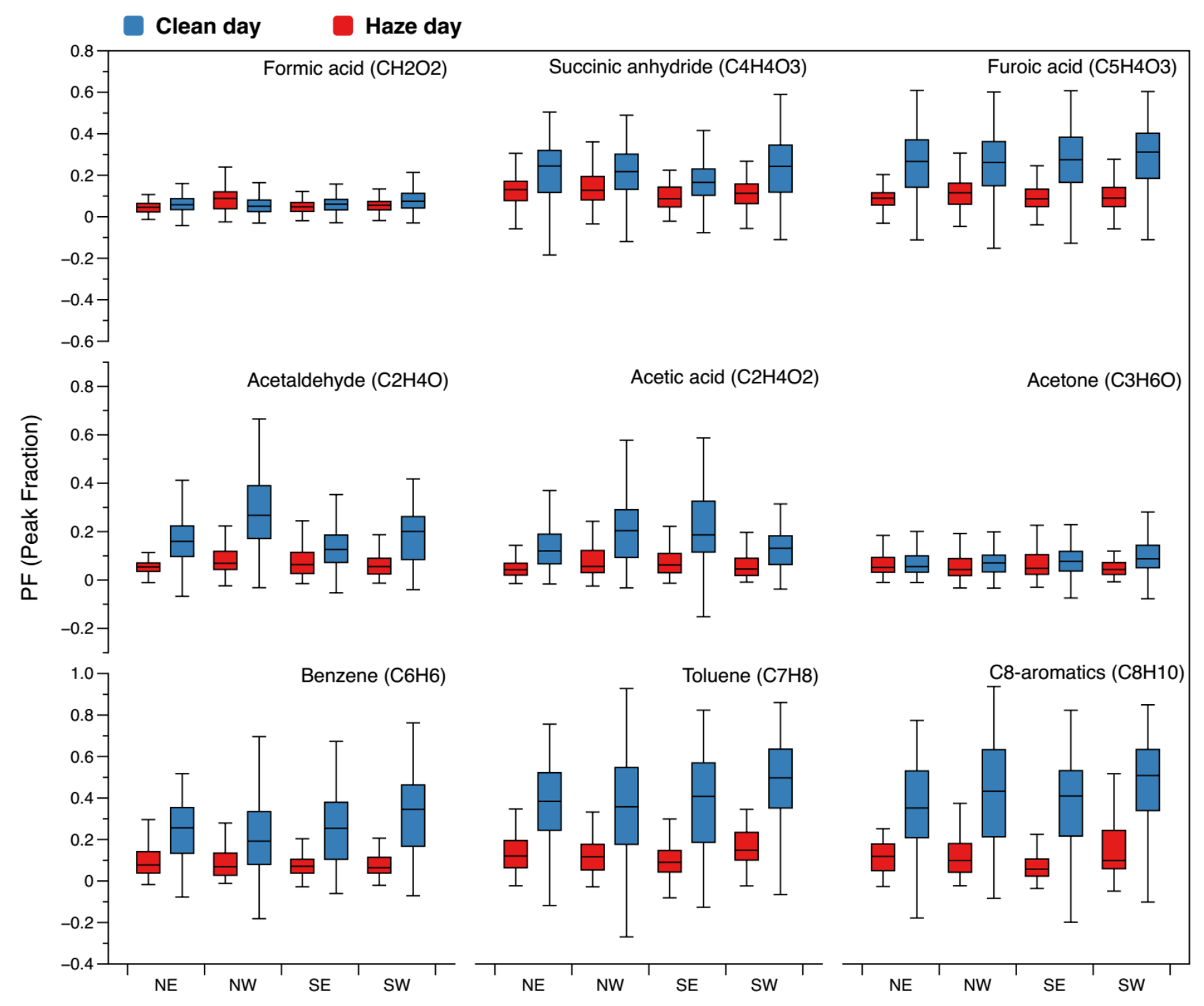

Figure 3. The spatial distributions of peak fraction values for common VOC species measured during the noon cycles from $\sim 11: 00$ AM to $\sim 12: 30$ PM for the clean day on 18 November 2018 and the haze day on 14 November 2018 . 

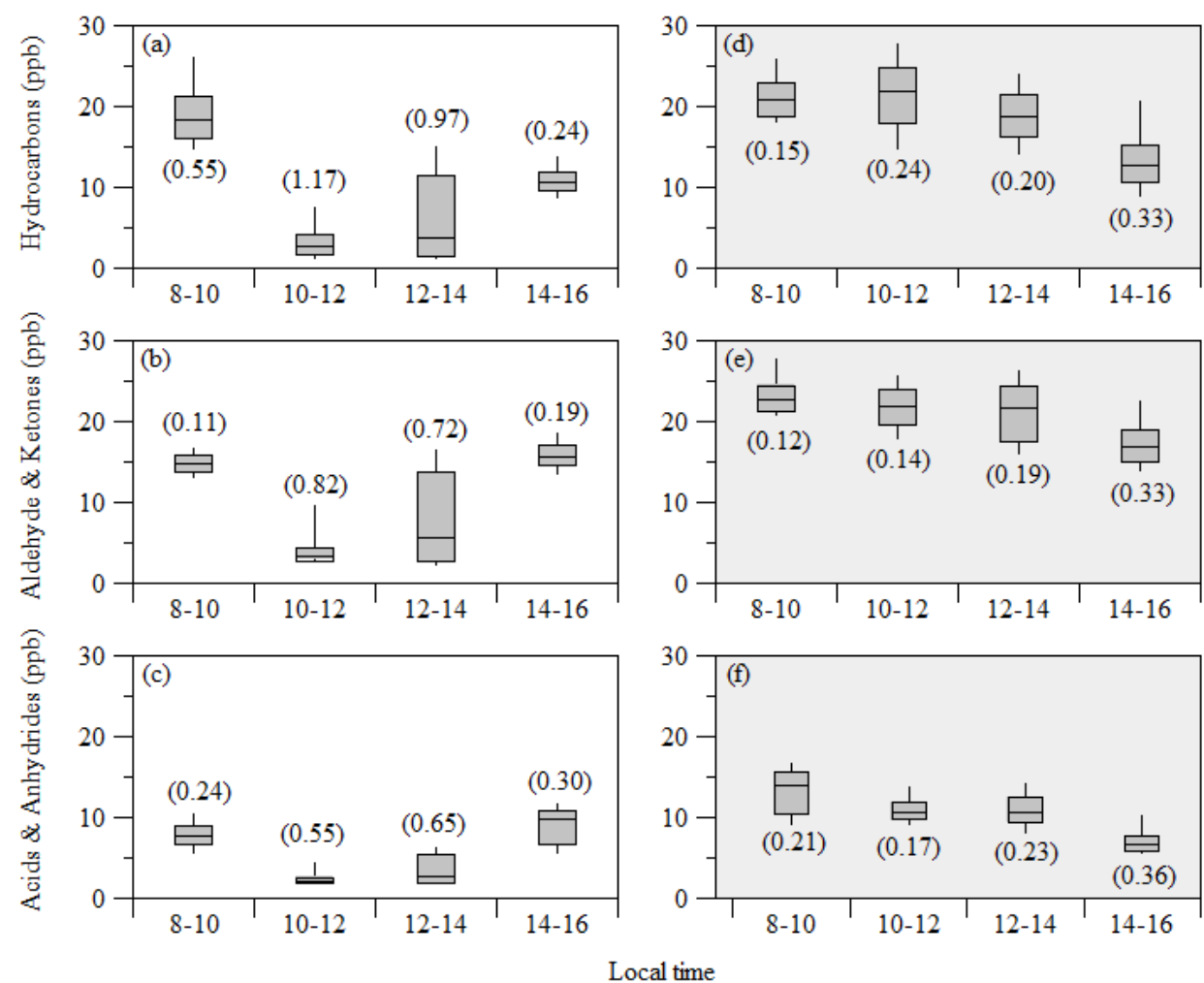

Figure 4. Spatial-temporal distributions of the concentrations of $\sum$ hydrocarbons, $\sum$ (aldehydes and ketones), and $\sum$ (acids and anhydrides) measured during the non-haze and haze days. The numbers in parentheses represent the CV values. The box and whisker plots show median, 75 th and 25 th percentiles, 90th and 10th percentiles. 
https://doi.org/10.5194/acp-2021-651

Preprint. Discussion started: 24 August 2021

(c) Author(s) 2021. CC BY 4.0 License.
Atmospheric

Chemistry and Physics
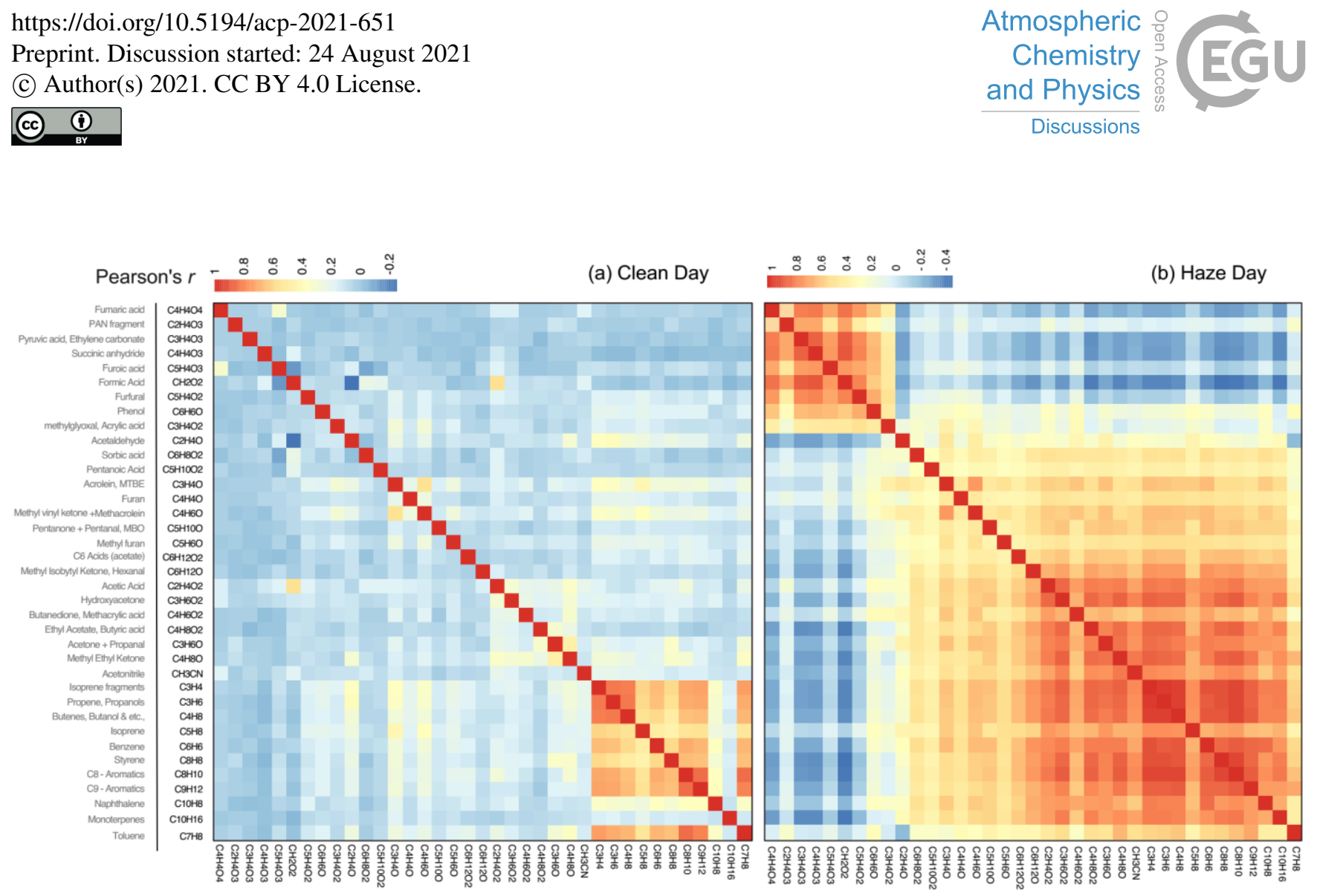

Figure 5. Correlation heatmaps for the concentrations of the main VOCs and OVOCs measured during (a) the clean day on 18 November 2018 and (b) the haze day on 14 November 2018. 
Table 1. The CV values for the concentrations or mass fractions of air pollutants measured during the noon cycles from $\sim 11: 00$ AM to $\sim 12: 30$ PM for the clean day on 18 November 2018 and the haze day on 14 November 2018.

\begin{tabular}{|c|c|c|c|c|c|}
\hline \multirow{2}{*}{\multicolumn{2}{|c|}{ Air pollutants }} & \multicolumn{2}{|c|}{ CV for concentration } & \multicolumn{2}{|c|}{$\mathrm{CV}$ for mass fraction } \\
\hline & & Clean & Haze & Clean & Haze \\
\hline \multirow{6}{*}{ NR-PM 2.5} & Total NR-PM 2.5 & 0.75 & 0.12 & $\mathrm{n} / \mathrm{a}$ & $\mathrm{n} / \mathrm{a}$ \\
\hline & Nitrate & 0.65 & 0.10 & 0.38 & 0.07 \\
\hline & Sulfate & 0.26 & 0.18 & 0.41 & 0.09 \\
\hline & Ammonium & 1.32 & 0.29 & 0.96 & 0.22 \\
\hline & Chloride & 0.99 & 0.12 & 0.94 & 0.04 \\
\hline & $\mathrm{OA}$ & 0.75 & 0.16 & 0.16 & 0.10 \\
\hline \multirow{3}{*}{$\mathrm{OA}$} & $\mathrm{HOA}$ & 0.79 & 0.33 & 0.53 & 0.29 \\
\hline & $\mathrm{COA}$ & 0.95 & 0.29 & 0.93 & 0.35 \\
\hline & OOA & 0.76 & 0.15 & 0.64 & 0.11 \\
\hline \multirow{6}{*}{$\begin{array}{c}\text { Detected VOCs and } \\
\text { OVOCs }\end{array}$} & Benzene & 0.81 & 0.23 & $\mathrm{n} / \mathrm{a}$ & $\mathrm{n} / \mathrm{a}$ \\
\hline & Toluene & 0.94 & 0.27 & $\mathrm{n} / \mathrm{a}$ & $\mathrm{n} / \mathrm{a}$ \\
\hline & $\Sigma$ Hydrocarbons & 0.96 & 0.23 & $\mathrm{n} / \mathrm{a}$ & $\mathrm{n} / \mathrm{a}$ \\
\hline & $\Sigma$ (Aldehyde \& Ketones) & 0.61 & 0.14 & $\mathrm{n} / \mathrm{a}$ & $\mathrm{n} / \mathrm{a}$ \\
\hline & $\Sigma$ (Acids \& Anhydrides) & 0.63 & 0.14 & $\mathrm{n} / \mathrm{a}$ & $\mathrm{n} / \mathrm{a}$ \\
\hline & Total & 0.68 & 0.16 & $\mathrm{n} / \mathrm{a}$ & $\mathrm{n} / \mathrm{a}$ \\
\hline \multirow{5}{*}{ Others } & $\mathrm{SO}_{2}$ & 0.13 & 0.27 & $\mathrm{n} / \mathrm{a}$ & $\mathrm{n} / \mathrm{a}$ \\
\hline & $\mathrm{CO}$ & 0.26 & 0.25 & $\mathrm{n} / \mathrm{a}$ & $\mathrm{n} / \mathrm{a}$ \\
\hline & NO & 0.22 & 0.26 & $\mathrm{n} / \mathrm{a}$ & $\mathrm{n} / \mathrm{a}$ \\
\hline & $\mathrm{NO}_{2}$ & 0.24 & 0.26 & $\mathrm{n} / \mathrm{a}$ & $\mathrm{n} / \mathrm{a}$ \\
\hline & $\mathrm{O}_{3}$ & 0.22 & 0.24 & $\mathrm{n} / \mathrm{a}$ & $\mathrm{n} / \mathrm{a}$ \\
\hline
\end{tabular}

